\title{
AS602801 Sensitizes Ovarian Cancer Stem Cells to Paclitaxel by Down-regulating MDR1
}

\author{
MASAHIRO YAMAMOTO ${ }^{1}$, SHUHEI SUZUKI ${ }^{1,2}$, KEITA TOGASHI $^{1,3}$, TOMOMI SANOMACHI ${ }^{1,2}$, \\ SHIZUKA SEINO ${ }^{1}$, CHIFUMI KITANAKA ${ }^{1,4}$ and MASASHI OKADA ${ }^{1}$ \\ Departments of ${ }^{1}$ Molecular Cancer Science, ${ }^{2}$ Clinical Oncology and ${ }^{3}$ Ophthalmology, \\ Yamagata University School of Medicine, Yamagata, Japan; \\ ${ }^{4}$ Research Institute for Promotion of Medical Sciences, Yamagata University Faculty of Medicine, Yamagata, Japan
}

\begin{abstract}
Background/Aim: AS602801, an anti-cancer stem cell (CSC) candidate drug, sensitizes ovarian CSCs to paclitaxel and carboplatin by reducing the expression of survivin, an anti-apoptotic protein. The aim of the study was to examine the effect of AS602801 on the expression of multi drug resistance protein 1 (MDR1). Materials and Methods: Using two ovarian CSC lines, A2780 CSLC and TOV-21G CSLC, mechanisms other than survivin down-regulation were examined by comparing the effects of AS602801 and $Y M 155$, an inhibitor of survivin. After screening for the expression of ATP-binding cassette $(A B C)$ transporters with or without AS602801 treatment, the sensitivity of cells to paclitaxel, carboplatin, and cisplatin was examined following knockdown of the ABC transporter. Results: The combinational effect of AS602801 on paclitaxel was less dependent on survivin than the effect on carboplatin. AS602801 reduced the expression of MDRl, an $A B C$ transporter. Knockdown of MDRl sensitized the cells to paclitaxel, but not to carboplatin or cisplatin. Conclusion: AS602801 chemosensitized ovarian CSCs to paclitaxel by reducing the expression of MDRI.
\end{abstract}

Ovarian cancer is the second most common gynecological cancer and the eighth leading cause of cancer-related death in women worldwide (1). Standard therapy for patients with advanced ovarian cancer is cytoreductive surgery followed by a combination of paclitaxel and platinum (2). Even though the initial treatment is effective in $70 \%$ of patients, cancer

Correspondence to: Masahiro Yamamoto and Masashi Okada, Department of Molecular Cancer Science, Yamagata University School of Medicine, Yamagata, 990-9585, Japan. Tel: +81 236285214, Fax: +81 236285215, e-mail: masahiro@med.id.yamagata-u.ac.jp (M.Y.), m-okada@med.id.yamagata-u.ac.jp (M.O.)

Key Words: Drug repositioning, drug repurposing, drug resistance, MDR1. recurrence with paclitaxel resistance frequently occurs (3-7). One of the mechanisms of recurrence and resistance is the presence of cancer stem cells (CSCs), that have high tumorinitiating capacity and are resistant to chemotherapeutic reagents $(8,9)$. Therefore, CSCs are a potential target of cancer chemotherapy (10).

There are multiple mechanisms of chemoresistance in CSCs: high expression levels of ATP-binding cassette (ABC) transporters, defects in apoptosis, efficient DNA damage repair, epithelial-mesenchymal transition, epigenetics, and a slow proliferation rate (11). Therapies targeting these CSCchemoresistant mechanisms are important to completely cure patients.

Recently, we reported that AS602801, a novel c-Jun $\mathrm{N}$-terminal kinase (JNK) inhibitor, chemosensitizes ovarian CSCs to carboplatin and paclitaxel (12). Our results suggested that the mechanism of chemosensitization is mediated by suppression of survivin, a member of the inhibitor of apoptosis (IAP) family. In this study, the contribution of survivin and other proteins on AS602801 chemosensitization was investigated.

\section{Materials and Methods}

Antibodies and reagents. An antibody against multidrug resistance protein 1 (MDR1, ab170904) was purchased from Abcam (Cambridge, UK). Antibodies against survivin (\#2808) and glyceraldehyde 3-phosphate dehydrogenase (GAPDH, \#5174) were purchased from Cell Signaling Technology, Inc. (Danvers, MA, USA). AS602801 and YM155 were purchased from ChemScene (Monmouth Junction, NJ, USA) and from AdooQ BioScience (Irvine, CA, USA), respectively. AS602801 and YM155 were dissolved in DMSO to prepare a 10 and $20 \mu \mathrm{M}$ stock solution, respectively. Carboplatin was purchased from FUJIFILM Wako Pure Chemical (Osaka, Japan) and dissolved in DMSO to prepare a $25 \mathrm{mM}$ stock solution. Paclitaxel was purchased from TOCRIS Bioscience (Bristol, UK) and dissolved in DMSO to prepare a $10 \mathrm{mM}$ stock solution. Cisplatin was purchased from FUJIFILM Wako Pure Chemical and dissolved in saline to prepare a $3.3 \mathrm{mM}$ stock solution. 
Table I. Sequences of primers for $q R T-P C R$

\begin{tabular}{lrr}
\hline Gene & Forward primer & Reverse primer \\
\hline ABCB 1 & 5'-CCCATCATTGCAATAGCAGG-3' & 5'-TGTTCAAACTTCTGCTCCTGA-3' \\
ABCB 4 & 5'-CTTTTCCTTGTCGCTGCTAAAT-3' \\
ABCC1 & 5'-ATGTCACGTGGAATACCAGC-3' & 5'-AGTTCAGTGGTGTCGTTGATGT-3' \\
ABCG2 & 5'-GCCACGTGATTCTTCCACAA-3' & 5'-GAAGACTGAACTCCCTTCCT-3' \\
BIRC5 & 5'-CCTTTCTCAAGGACCACCGCATC-3' & 5'-TGGCTGTCATGGCTTCAGTA-3' \\
GAPDH & 5'-ACCATCTTCCAGGAGCGAGAT-3' & 5'-CGTCATCTGGCTCCCAGCCTT-3' \\
\hline
\end{tabular}

Cell culture. The establishment and characterization of human CSCs (A2780 CSLC and TOV-21G CSLC) have been previously described (12-15). These cells were maintained as monolayers under appropriate stem cell culture conditions. Briefly, the cells were cultured on collagen I-coated dishes (IWAKI, Tokyo, Japan) in stem cell culture medium consisting of DMEM/F12 medium supplemented with 1\% B27 (Thermo Fisher Scientific, Waltham, MA, USA), $20 \mathrm{ng} / \mathrm{ml}$ epidermal growth factor (EGF) and fibroblast growth factor 2 (FGF2) (Peprotech, Inc., Rocky Hill, NJ, USA), D(+)-glucose (final concentration=26.2 $\mathrm{mM}$ ), L-glutamine (final concentration $=4.5 \mathrm{mM}$ ), 100 units $/ \mathrm{ml}$ penicillin, and $100 \mu \mathrm{g} / \mathrm{ml}$ streptomycin. The stem cell culture medium was changed approximately every 3 days, and EGF and FGF2 were added to the culture medium every day. The authenticity of the cells was verified by genotyping short tandem repeat (STR) loci (Bio-Synthesis, Inc., Lewisville, TX, USA) followed by comparison to the American Type Culture Collection STR Database for Human Cell Lines (http://www.atcc.org/STR_Database.aspx).

Immunoblot analysis. Immunoblot analysis was conducted as previously described (13-17). Drug-treated ovarian CSCs were washed with ice-old phosphate-buffered saline and lysed in RIPA buffer $[10 \mathrm{mM}$ Tris/ $\mathrm{HCl}(\mathrm{pH} 7.4), 0.1 \%$ sodium dodecyl sulfate (SDS), $0.1 \%$ sodium deoxycholate, $1 \% \mathrm{NP}-40,150 \mathrm{mM} \mathrm{NaCl}, 1 \mathrm{mM}$ EDTA, $1.5 \mathrm{mM} \quad \mathrm{Na}_{3} \mathrm{VO}_{4}, 10 \mathrm{mM} \quad \mathrm{NaF}, 10 \mathrm{mM}$ sodium pyrophosphate, $10 \mathrm{mM}$ sodium $\beta$-glycerophosphate, and $1 \%$ protease inhibitor cocktail set III (Wako Pure Chemical Industries, Ltd)]. This was followed by the immediate addition of the same volume of $2 x$ Laemmli buffer [125 mM Tris/HCl (pH 6.8), 4\% SDS, 10\% glycerol] and boiling at $95^{\circ} \mathrm{C}$ for $10 \mathrm{~min}$. Protein concentration was determined using a BCA protein assay kit (Thermo Fisher Scientific). Samples containing equal amounts of protein were resolved by SDSpolyacrylamide gel electrophoresis and transferred to polyvinylidene fluoride membranes. The membranes were probed with a primary antibody and subsequently with horseradish peroxidase (HRP)conjugated secondary antibody, as recommended by the manufacturer of each antibody. Specific bands were visualized using Immobilon Western Chemiluminescent HRP Substrate (Merck Millipore, Billerica, MA, USA) and detected semi-quantitatively by a ChemiDoc Touch Imaging System (Bio-Rad, Hercules, CA, USA).

Gene silencing by siRNA. siRNAs against human MDR1 (ABCB1; \#1 HSS 107918, \#2 HSS107919, and \#3 HSS182278) and Medium GC Duplex \#2 of Stealth RNAi siRNA Negative Control Duplexes (non-targeting control, siControl\#1) were purchased from Thermo Fisher Scientific. MISSION siRNA Negative Control (SIC-001, siControl\#2) was purchased from MilliporeSigma (St. Louis, MO, USA). A2780 CSLCs or TOV-21G CSLCs were transiently transfected with siRNAs against MDR1 (siMDR1) or with control RNAs (siControl) using Lipofectamine RNAiMAX (Thermo Fisher Scientific) according to the manufacturer's instructions.

Cell viability assay. Cell viability assays were performed as previously described (13). Briefly, cell viability was determined by the tetrazolium salt reduction method using the WST- 8 assay (Cell Counting Kit-8; Dojindo Laboratories, Kumamoto, Japan) according to the manufacturer's instructions. Cells $(500$ cells/well) plated in 96-well collagen I-coated plates were treated the next day with drugs for 3 days followed by culture in the absence of any drug for another 3 days. WST- 8 reagent was then added, and the cells were incubated for $1-3 \mathrm{~h}$ at $37^{\circ} \mathrm{C}$. Absorbance at $450 \mathrm{~nm}$ was measured using a microplate reader (Model 680, Bio-Rad). Relative cell viability was calculated as a percentage of the absorbance of treated samples relative to that of control samples. Cell viability assays were performed in four or six replicates.

Quantitative reverse transcription PCR. A2780 CLSCs and TOV-21G CLSCs were treated with or without AS602801 (7.5 $\mu \mathrm{M})$ for 3 days, and then RNA was extracted from the cells using a TRIzol reagent (Thermo Fisher Scientific). The RNA was reverse-transcribed into cDNA using PrimeScript II 1st strand cDNA Synthesis Kit (Takara Bio, Kusatsu, Japan). Quantitative PCR using the cDNA samples was performed with a Thunderbird SYBR qPCR Mix (Toyobo, Osaka, Japan) using StepOnePlus Real-time PCR system (Thermo Fisher Scientific). The mRNA levels were calculated by the $\Delta \Delta C t$ method and normalized to the values of GAPDH. The sequences of the gene specific primer sets are listed in Table I.

Statistical analysis. The results were expressed as the mean and standard deviation (SD), and differences were compared using the Student's $t$-test or one-way Analysis of Variance (ANOVA) with Tukey's post-hoc test by Prism 8 software (Graph Pad, San Diego, CA, USA). $p$-Values of less than 0.05 were considered significant.

\section{Results}

Down-regulation of survivin is not the only mechanism of chemosensitization by AS602801 in A2780 CSLC. We recently reported that AS602801 sensitizes A2780 CSLC, an ovarian CSC line, to paclitaxel and carboplatin by downregulating survivin, an anti-apoptotic protein (12). To explore if down-regulation of survivin is the only mechanism of chemosensitization by AS602801, A2780 CSLCs were treated with paclitaxel or carboplatin in the presence or 


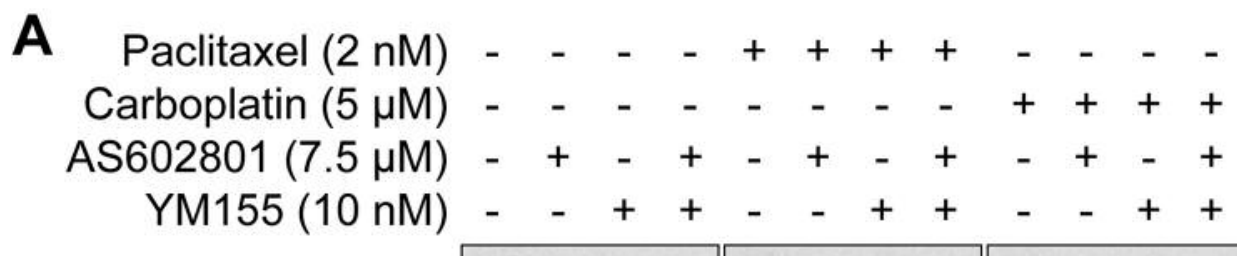

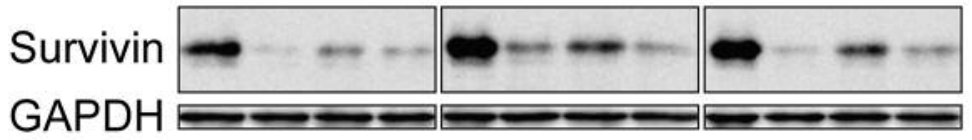

B

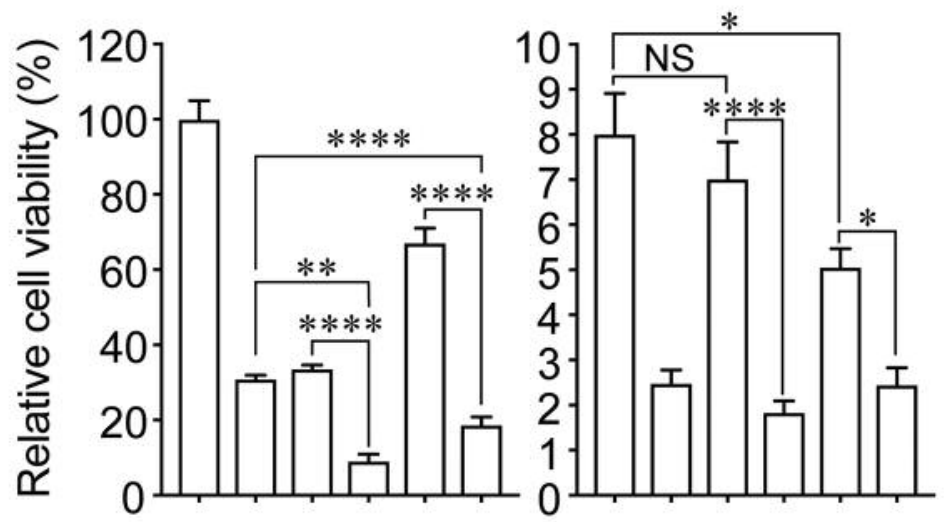

Paclitaxel $(2 \mathrm{nM})-\quad++-$

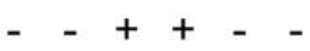

Carboplatin $(5 \mu \mathrm{M}) \quad-\quad-\quad++$

AS602801 (7.5 $\mu \mathrm{M})$ - + - + + +

YM155 (10 nM)

C

D

- $-\quad-++$

- + - -+

$+++++$
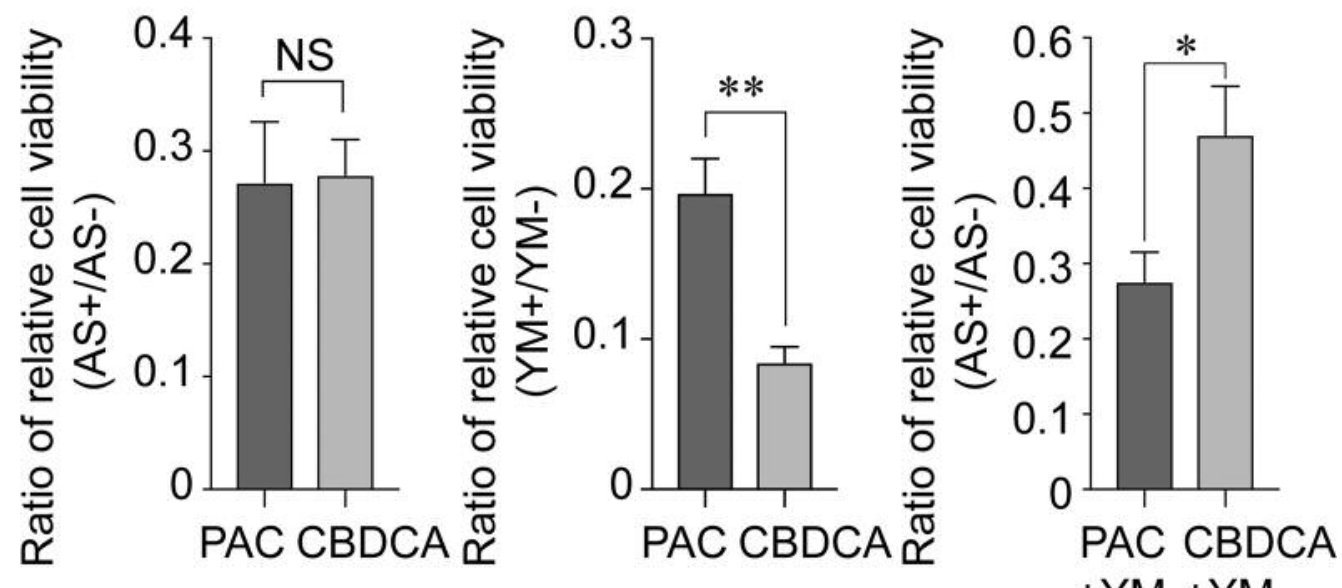

Figure 1. Inhibition of survivin affects paclitaxel less than carboplatin, which suggests that other mechanisms are involved in the suppression of cell growth by AS602801. A2780 CSLCs were treated with paclitaxel $(2 \mathrm{nM})$ or carboplatin $(5 \mu M)$ in the presence or absence of AS602801 (7.5 $\mu M)$ and/or YM155 (10 nM) for 3 days, and then subjected to western blot analysis of survivin and glyceraldehyde 3-phosphate dehydrogenase (GAPDH) (A). The drug-treated cells were incubated for another 3 days without any drug, and then cells were subjected to a WST-8 assay (B). The ratio of cell viability of cells treated with paclitaxel (PAC) or carboplatin (CBDCA) in the presence of AS602801 (AS+) was compared to that in the absence of AS602801 $(A S-)(C)$. The ratio of cell viability of cells treated with paclitaxel or carboplatin in the presence of $Y M 155(Y M+)$ was compared to that in the absence of YM155 (YM-) (D). The ratio of cell viability of cells treated with paclitaxel and YM155 (PAC+YM) or carboplatin and YM155 (CBDCA+YM) in the presence of AS602801 was compared to that in the absence of AS602801 (E). The values represent means $+S D$ from samples in six replicates of a representative experiment repeated with similar results. NS $p>0.05,{ }^{*} p<0.05,{ }^{*} p<0.01$, and $*^{* * *} p<0.0001$. 
A A2780 CSLC BIRC5

(Survivin)
ABCB1

(MDR1)
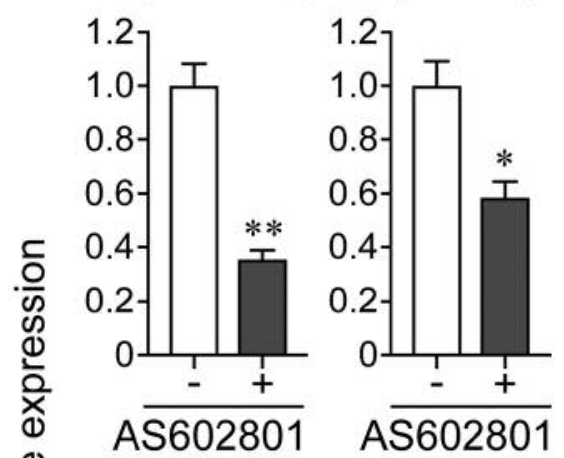

C TOV-21G CLSC

(MDR3)

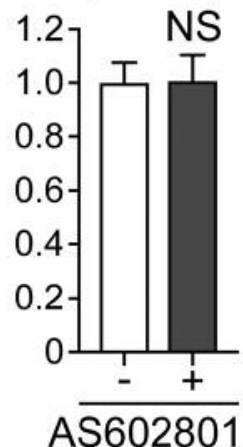

ABCC1 (MRP1)
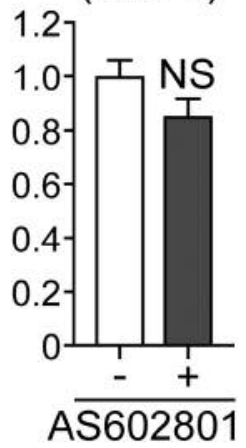
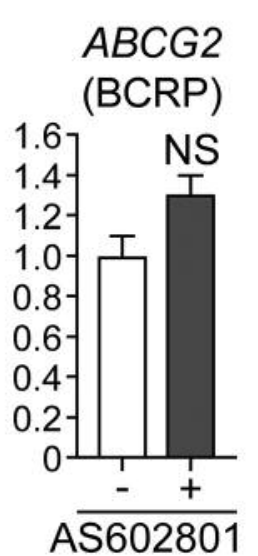
BIRC5

(Survivin)
ABCB1

(MDR1)
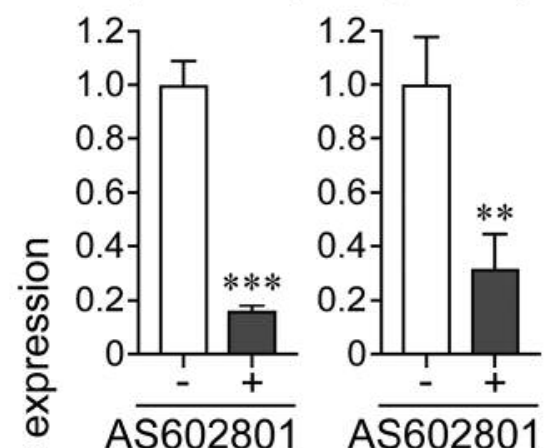

ABCC1

(MRP1)

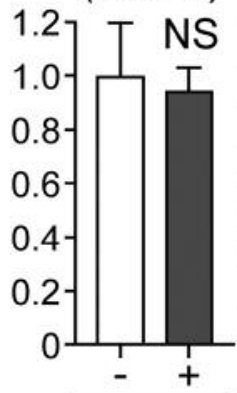

A $\overline{5602801}$
ABCB4

(MDR3)

Not

detected

\section{B TOV-21G CSLC}
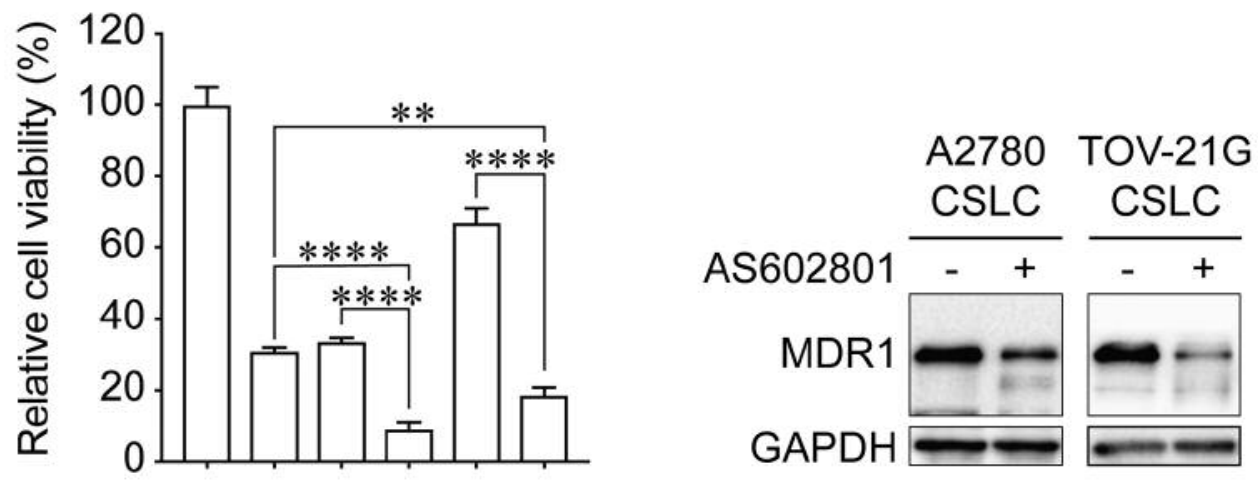

AS602801 (7.5 $\mu \mathrm{M})$

Paclitaxel (2 nM)

\section{Carboplatin $(5 \mu \mathrm{M})$}

Figure 2. Effects of AS602801 on the mRNA and protein expression of ABC transporters in A2780 CLSC and TOV-21G CSLC. A2780 CLSCs and TOV-21G CLSCs were treated with AS602801 (7.5 $\mu \mathrm{M})$ for 3 days; then the mRNA expression of BIRC5 and ABC transporters was quantified by RT-qPCR (A and C), and protein expression of multidrug resistance protein 1 (MDR1) and glyceraldehyde 3-phosphate dehydrogenase (GAPDH) was evaluated by western blot (D). TOV-21G CSLCs were treated with paclitaxel or carboplatin in the presence or absence of AS602801 for 3 days followed by incubation without any drugs for another 3 days, and then the cells were subjected to a WST-8 assay $(B)$. In $(A),(B)$, and $(C)$, the values represent means $+S D$ of four replicates $(A$ and $C)$ or six replicates $(B)$ of a representative experiment repeated with similar results. In $(A)$ and $(C)$, NS $p>0.05, * p<0.05$, ** $p<0.01$, and $*^{* *} p<0.001$, compared to control. In $(B), * * p<0.01$ and $* * * * p<0.0001$. 


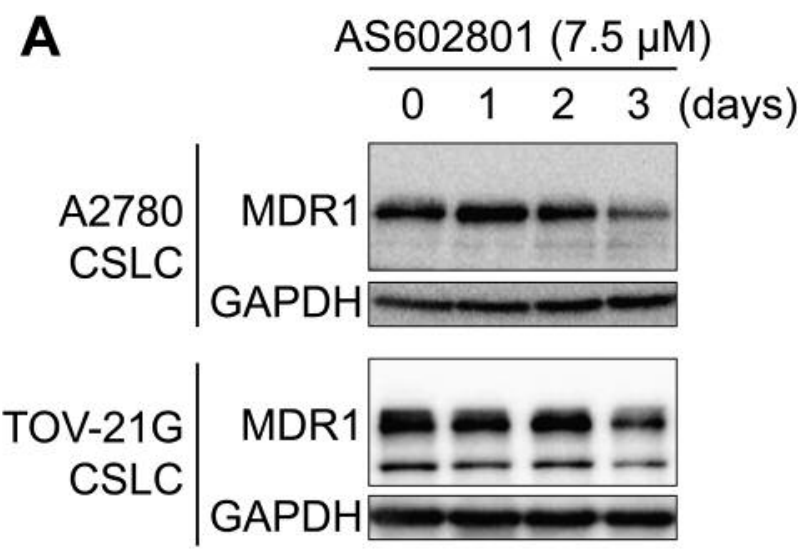

B
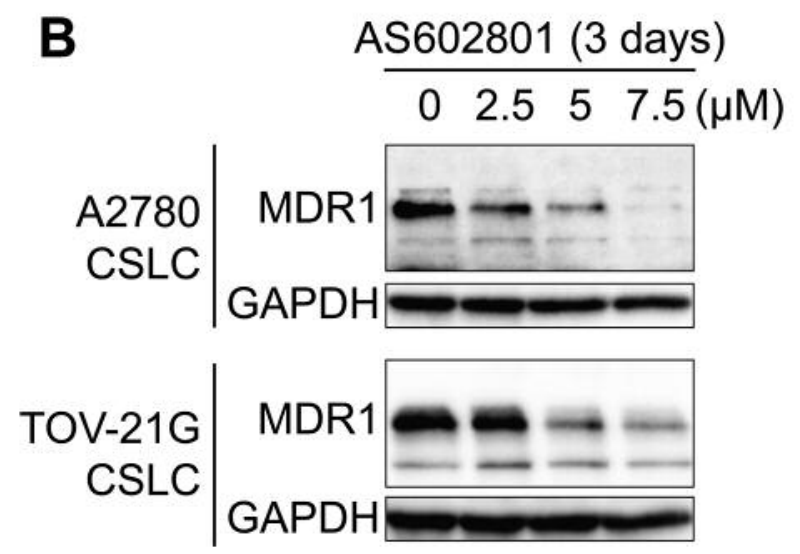

Figure 3. AS602801 reduces the expression of MDR1 in a time- and dose-dependent manner. A2780 CSLCs and TOV-21G CLSCs were treated with AS602801 at $7.5 \mu M$ for the indicated time (A) and at the indicated concentration for 3 days $(B)$. The cells were then subjected to western blot analysis of multidrug resistance protein 1 (MDR1) and glyceraldehyde 3-phosphate dehydrogenase (GAPDH).

absence of AS602801 and/or YM155, an inhibitor of survivin, and then expression of survivin and cell viability were examined (Figure 1A and B). Both AS602801 and YM155 reduced the expression of survivin in the absence or presence of paclitaxel or carboplatin (Figure 1A). In the cell viability assay, AS602801 clearly had significant combinational effects with paclitaxel and carboplatin, but the effects of YM155 on paclitaxel were not significant, which was similar to a previous study (12) (Figure 1B, the cells treated with YM155 vs. the cells treated with paclitaxel and YM155). Because this result suggests that AS602801 affects paclitaxel and carboplatin in a different manner from YM155, the effects of AS602801 and YM155 on paclitaxel and carboplatin were carefully compared. Comparison of the ratio of cell viability in the presence of AS602801 to that in the absence of AS602801 (AS+/AS-) between paclitaxel- treated (PAC) and carboplatin-treated cells (CBDCA) revealed that AS602801 decreased cell viability in cells treated with carboplatin and paclitaxel to the same extent (Figure 1C). On the other hand, comparing the ratio of cell viability in the presence of YM155 to that in the absence of YM155 (YM+/YM-) between paclitaxel-treated cells and carboplatin-treated cells revealed that YM155 decreased cell viability significantly more in carboplatin-treated cells (Figure 1D). Although both AS602801 and YM155 reduced the expression of survivin, these drugs contribute differently to the combinational inhibitory effects of paclitaxel and carboplatin. Furthermore, in the presence of YM155, AS602801 decreased cell viability significantly less in carboplatin-treated cells than in paclitaxel-treated cells (Figure 1E). These data suggest that the combinational effect of AS602801 on paclitaxel was less dependent on survivin than the effect on carboplatin and raise the possibility that other mechanism(s) are affected by the combinational effects of AS602801 and other drugs, especially paclitaxel.

The expression of MDR1 is reduced by AS602801 in ovarian CSCs. One of the mechanisms of chemoresistance in CSCs is to expel chemotherapeutic reagents out of cells by $\mathrm{ABC}$ transporters. Because multidrug resistance protein 1 (MDR1, P-glycoprotein or ABCB1), MDR3 (or ABCB4), MDRassociated protein 1 (MRP1 or $A B C C 1$ ), and breast cancer resistance protein (BCRP or $\mathrm{ABCG} 2$ ) are $\mathrm{ABC}$ transporters involved in multidrug resistance $(18,19)$, the effects of AS602801 on the mRNA levels of these transporters and survivin were examined by RT-qPCR. In accordance with the reduced protein expression of survivin by AS602801, the mRNA expression of survivin was significantly reduced by AS602801 treatment (Figure 2A). Although the expression of $\mathrm{ABCB} 4, \mathrm{ABCC} 1$, and $\mathrm{ABCG} 2$ was not altered by AS602801, the expression of ABCB1 was significantly reduced by AS602801. To confirm if suppression of ABCB1 by AS602801 was observed in another ovarian CSC line, TOV-21G CSLCs were used in which AS602801 had a combinational growth inhibitory effect with paclitaxel and carboplatin (Figure 2B). Similar to A2780 CSLC, the mRNA levels of ABCB1 were significantly reduced by AS602801 in TOV-21G CSLC (Figure 2C). AS602801 reduced the protein levels of MDR1, the protein product of ABCB1, in both cell lines (Figure 2D). The reduction in MDR1 expression in these cell lines occured in a time- and dosedependent manner (Figure 3A and B).

Knockdown of MDRI by siRNA sensitizes ovarian CSCs to paclitaxel, but not to carboplatin and cisplatin. To confirm that down-regulation of MDR 1 by AS602801 contributes to the combinational effects with paclitaxel and carboplatin, the expression of MDR1 was knocked down by siRNA, and the combinational inhibitory effects with paclitaxel, 
carboplatin, and cisplatin, another platinum reagent used for ovarian cancer, were examined. Knockdown by three different siRNAs reduced the expression of MDR1 in A2780 CSLC and TOV-21G CSLC (Figure 4A). Compared with the viability of cells treated with control siRNAs (siControl\#1 and \#2), the viability of cells treated with siMDRs was significantly decreased by paclitaxel, but not by carboplatin or cisplatin in A2780 CLSC and TOV-21G CSLC (Figure 4B and C). These results suggest that downregulation of MDR1 by AS602801 contributes to chemosensitization to paclitaxel.

\section{Discussion}

First-line chemotherapy against advanced ovarian cancer by a combination of paclitaxel and platinum has a high response rate. However, regrowth of cancer cells with a chemoresistant phenotype is inevitable (20). Multidrug resistance (MDR) is a phenomenon where cancer cells show resistance to a broad spectrum of chemotherapeutic drugs that do not share functional and structural characteristics. There are several mechanisms of MDR, and CSCs may be involved $(11,21)$. CSCs are a minor population within cancer tissues, proliferate slowly, and have the potential for self-renewal and differentiation into the tumor cells that comprise the majority of cancer tissues. CSCs have high tumor initiation activity and chemoresistance; therefore, CSCs are a major source of tumor recurrence. There are multiple mechanisms of chemoresistance in CSCs: increased drug export, inactivation of drugs, enhanced DNA damage repair, slow proliferation and dormancy, suppression of apoptosis, and epithelial-mesenchymal transition (22). In ovarian cancer, CSCs contribute to recurrence after chemotherapy $(23,24)$ and are a chemotherapy target. We reported that AS602801, an anti-CSC drug (17), sensitizes ovarian CSCs to paclitaxel and carboplatin by reducing the expression of survivin, an anti-apoptotic protein (12). This study showed that the reduction of survivin is not the only mechanism of chemosensitization, especially for paclitaxel.

There are $49 \mathrm{ABC}$ transporters divided into seven categories, $A$ to $G$ (25). Multidrug resistance protein 1 (MDR1, P-glycoprotein or ABCB1), MDR3 (or ABCB4), MDR-associated protein 1 (MRP1 or ABCC1), and breast cancer resistance protein (BCRP or $\mathrm{ABCG} 2$ ) are mainly involved in chemoresistance $(18,19)$. After screening for altered mRNA expression of these genes in two ovarian CSCs, A2780 CSLC and TOV-21G CSLC, AS602801 was found to reduce the expression of $\mathrm{ABCB} 1$ but not the other genes. AS602801 reduced MDR1 protein levels in a time- and dosedependent manner in both ovarian CSCs. MDR1 is a membrane glycoprotein that effluxes chemotherapeutic reagents including taxanes, anthracyclines, and vinca alkaloids
(26). The increased expression of MDR1 is correlated with poor responsiveness to chemotherapeutic drugs in acute myelogenous leukemia (27), small cell lung cancer (28), breast cancer (29), and ovarian cancer $(30,31)$. The expression of MDR1 is increased in the CSCs of acute leukemia (32), glioblastoma $(33,34)$, breast cancer $(35)$, renal cell carcinoma (36), and ovarian cancer $(24,37,38)$. In accordance with our results showing that down-regulation of MDR1 sensitized ovarian CSCs to paclitaxel rather than to cisplatin or carboplatin, knockdown of MDR1 by shRNA in A2780 cells sensitized cells to paclitaxel, docetaxel, and vincristine but not to cisplatin (39). Furthermore, drug sensitivity to taxanes, doxorubicin, vinblastine, and bisantrene is negatively correlated with the expression levels of MDR1 in the NCI-60 cancer cell line panel (40). These results suggest that downregulation of MDR1 by AS602801 contributes to chemosensitization to paclitaxel in ovarian CSCs.

MDR1 is expressed in several normal tissues including the bronchopulmonary epithelium, hepatobiliary epithelium, renal tubular epithelium, endothelium in the blood-brain barrier, and trophoblasts in the placenta to protect against xenobiotics $(41,42)$. Because of the distribution of MDR1 in normal tissues, drugs targeting MDR1 may cause side effects. In clinical trials of drugs targeting MDR1, there were no clinical benefits mainly because of toxicity $(43,44)$. AS602801, at the concentration used in this study, was not toxic to IMR-90 cells, a normal human fibroblast cell line (17). Although the effects of AS602801 on the expression of MDR1 in normal tissues were not investigated, the safety of AS602801 has already been examined in a clinical trial of patients with endometriosis (NCT01630252), which suggested that AS602801 is a good candidate drug targeting MDR1 without harmful side effects.

In this study, a new mechanism of chemosensitization of ovarian CSCs to paclitaxel by AS602801 was revealed: reduction of MDR1 expression. Our results suggest that the combination of AS602801 with the standard chemotherapeutic drugs paclitaxel and cisplatin or carboplatin for the treatment of ovarian cancer improves prognosis through chemosensitization by reducing expression of both MDR1 and survivin. In addition, our data imply a possible therapeutic application of AS602801 in other types of cancers overexpressing MDR1 and/or survivin.

\section{Conflicts of Interest}

The Authors declare no conflict of interest in regard to this study.

\section{Authors' Contributions}

M.Y., C.K., and M.O. designed the research. M.Y. and M.O. wrote the paper. M.Y. and S. Seino performed the experiments. S. Suzuki, K.T., and T.S. analyzed and interpreted the data. All Authors discussed the results and contributed to the final manuscript. 


\section{Acknowledgements}

The Authors would like to thank Ms. Asuka Sugai for her secretarial contributions to this study. This work was supported by Grants-inAid for Young Scientists from the Ministry of Education, Culture, Sports, Science and Technology of Japan.

\section{References}

1 Ferlay J, Soerjomataram I, Dikshit R, Eser S, Mathers C, Rebelo M, Parkin DM, Forman D and Bray F: Cancer incidence and mortality worldwide: sources, methods and major patterns in GLOBOCAN 2012. Int J Cancer 136: E359-386, 2015. PMID: 25220842, DOI: $10.1002 /$ ijc. 29210

2 Ledermann JA, Raja FA, Fotopoulou C, Gonzalez-Martin A, Colombo N, Sessa C and Group EGW: Newly diagnosed and relapsed epithelial ovarian carcinoma: ESMO Clinical Practice Guidelines for diagnosis, treatment and follow-up. Ann Oncol 24: vi24-32, 2013. PMID: 24078660, DOI: 10.1093/ annonc/mdt333

3 Heintz AP, Odicino F, Maisonneuve P, Quinn MA, Benedet JL, Creasman WT, Ngan HY, Pecorelli S and Beller U: Carcinoma of the ovary. FIGO 26th Annual Report on the Results of Treatment in Gynecological Cancer. Int J Gynaecol Obstet 95: S161-192, 2006. PMID: 17161157, DOI: 10.1016/S0020-7292(06)60033-7

4 Monk BJ and Coleman RL: Changing the paradigm in the treatment of platinum-sensitive recurrent ovarian cancer: from platinum doublets to nonplatinum doublets and adding antiangiogenesis compounds. Int J Gynecol Cancer 19: S63-67, 2009. PMID: 19955917, DOI: 10.1111/IGC.0b013e3181c104fa

5 Cannistra SA: Cancer of the ovary. N Engl J Med 351: 25192529, 2004. PMID: 15590954 , DOI: 10.1056/NEJMra041842

6 Bookman MA: First-line chemotherapy in epithelial ovarian cancer. Clin Obstet Gynecol 55: 96-113, 2012. PMID: 22343232, DOI: $10.1097 /$ GRF.0b013e31824b45da

7 Harter P, Hilpert F, Mahner S, Heitz F, Pfisterer J and du Bois A: Systemic therapy in recurrent ovarian cancer: current treatment options and new drugs. Expert Rev Anticancer Ther 10: 81-88, 2010. PMID: 20014888, DOI: 10.1586/era.09.165

8 Beck B and Blanpain C: Unravelling cancer stem cell potential. Nat Rev Cancer 13: 727-738, 2013. PMID: 24060864, DOI: $10.1038 / \mathrm{nrc} 3597$

9 Maugeri-Sacca M, Vigneri P and De Maria R: Cancer stem cells and chemosensitivity. Clin Cancer Res 17: 4942-4947, 2011. PMID: 21622723, DOI: 10.1158/1078-0432.CCR-10-2538

10 Wang T, Shigdar S, Gantier MP, Hou Y, Wang L, Li Y, Shamaileh HA, Yin W, Zhou SF, Zhao X and Duan W: Cancer stem cell targeted therapy: progress amid controversies. Oncotarget 6: 44191-44206, 2015. PMID: 26496035, DOI: $10.18632 /$ oncotarget.6176

11 Mihanfar A, Aghazadeh Attari J, Mohebbi I, Majidinia M, Kaviani M, Yousefi M and Yousefi B: Ovarian cancer stem cell: A potential therapeutic target for overcoming multidrug resistance. J Cell Physiol 234: 3238-3253, 2019. PMID: 30317560, DOI: $10.1002 /$ jcp.26768

12 Yamamoto M, Suzuki S, Togashi K, Sanomachi T, Seino S, Kitanaka C and Okada M: AS602801, an anticancer stem cell candidate drug, reduces survivin expression and sensitizes A2780 ovarian cancer stem cells to carboplatin and paclitaxel. Anticancer Res 38: 6699-6706, 2018. PMID: 30504379, DOI: 10.21873/anticanres.13038
13 Togashi K, Okada M, Yamamoto M, Suzuki S, Sanomachi T, Seino S, Yamashita $\mathrm{H}$ and Kitanaka C: A small-molecule kinase inhibitor, CEP-1347, inhibits survivin expression and sensitizes ovarian cancer stem cells to paclitaxel. Anticancer Res 38: 45354542, 2018. PMID: 30061219, DOI: 10.21873/anticanres.12757

14 Seino M, Okada M, Shibuya K, Seino S, Suzuki S, Takeda H, Ohta T, Kurachi H and Kitanaka C: Differential contribution of ROS to resveratrol-induced cell death and loss of self-renewal capacity of ovarian cancer stem cells. Anticancer Res 35: 85-96, 2015. PMID: 25550538

15 Seino M, Okada M, Shibuya K, Seino S, Suzuki S, Ohta T, Kurachi $\mathrm{H}$ and Kitanaka C: Requirement of JNK signaling for self-renewal and tumor-initiating capacity of ovarian cancer stem cells. Anticancer Res 34: 4723-4731, 2014. PMID: 25202050

16 Sakaki H, Okada M, Kuramoto K, Takeda H, Watarai H, Suzuki S, Seino S, Seino M, Ohta T, Nagase S, Kurachi H and Kitanaka C: GSKJ4, A selective Jumonji H3K27 demethylase inhibitor, effectively targets ovarian cancer stem cells. Anticancer Res 35: 6607-6614, 2015. PMID: 26637876

17 Okada M, Kuramoto K, Takeda H, Watarai H, Sakaki H, Seino S, Seino M, Suzuki S and Kitanaka C: The novel JNK inhibitor AS602801 inhibits cancer stem cells in vitro and in vivo. Oncotarget 7: 27021-27032, 2016. PMID: 27027242, DOI: 10.18632/oncotarget.8395

18 Fletcher JI, Williams RT, Henderson MJ, Norris MD and Haber $\mathrm{M}$ : $\mathrm{ABC}$ transporters as mediators of drug resistance and contributors to cancer cell biology. Drug Resist Updat 26: 1-9, 2016. PMID: 27180306, DOI: 10.1016/j.drup.2016.03.001

19 Duan Z, Brakora KA and Seiden MV: Inhibition of ABCB1 (MDR1) and ABCB4 (MDR3) expression by small interfering RNA and reversal of paclitaxel resistance in human ovarian cancer cells. Mol Cancer Ther 3: 833-838, 2004. PMID: 15252144

20 Agarwal R and Kaye SB: Ovarian cancer: strategies for overcoming resistance to chemotherapy. Nat Rev Cancer 3: 502516, 2003. PMID: 12835670, DOI: $10.1038 / \mathrm{nrc} 1123$

21 Dean M, Fojo T and Bates S: Tumour stem cells and drug resistance. Nat Rev Cancer 5: 275-284, 2005. PMID: 15803154, DOI: $10.1038 / \mathrm{nrc} 1590$

22 Zhao J: Cancer stem cells and chemoresistance: The smartest survives the raid. Pharmacol Ther 160: 145-158, 2016. PMID: 26899500, DOI: 10.1016/j.pharmthera.2016.02.008

$23 \mathrm{Hu}$ L, McArthur C and Jaffe RB: Ovarian cancer stem-like sidepopulation cells are tumourigenic and chemoresistant. $\mathrm{Br} \mathrm{J}$ Cancer 102: 1276-1283, 2010. PMID: 20354527, DOI: 10.1038/sj.bjc.6605626

24 Rizzo S, Hersey JM, Mellor P, Dai W, Santos-Silva A, Liber D, Luk L, Titley I, Carden CP, Box G, Hudson DL, Kaye SB and Brown R: Ovarian cancer stem cell-like side populations are enriched following chemotherapy and overexpress EZH2. Mol Cancer Ther 10: 325-335, 2011. PMID: 21216927, DOI: 10.1158/1535-7163.MCT-10-0788

25 Fletcher JI, Haber M, Henderson MJ and Norris MD: ABC transporters in cancer: more than just drug efflux pumps. Nat Rev Cancer 10: 147-156, 2010. PMID: 20075923, DOI: $10.1038 / \mathrm{nrc} 2789$

$26 \mathrm{Choi} \mathrm{CH}$ : $\mathrm{ABC}$ transporters as multidrug resistance mechanisms and the development of chemosensitizers for their reversal. Cancer Cell Int 5: 30, 2005. PMID: 16202168, DOI: $10.1186 / 1475-2867-5-30$ 
27 Leith CP, Kopecky KJ, Chen IM, Eijdems L, Slovak ML, McConnell TS, Head DR, Weick J, Grever MR, Appelbaum FR and Willman CL: Frequency and clinical significance of the expression of the multidrug resistance proteins MDR1/Pglycoprotein, MRP1, and LRP in acute myeloid leukemia: a Southwest Oncology Group Study. Blood 94: 1086-1099, 1999. PMID: 10419902

28 Triller N, Korosec P, Kern I, Kosnik M and Debeljak A: Multidrug resistance in small cell lung cancer: expression of $\mathrm{P}$ glycoprotein, multidrug resistance protein 1 and lung resistance protein in chemo-naive patients and in relapsed disease. Lung Cancer 54: 235-240, 2006. PMID: 16934363, DOI: 10.1016/ j.lungcan.2006.06.019

29 Trock BJ, Leonessa F and Clarke R: Multidrug resistance in breast cancer: a meta-analysis of MDR1/gp170 expression and its possible functional significance. J Natl Cancer Inst 89: 917931, 1997. PMID: 9214671

30 Patch AM, Christie EL, Etemadmoghadam D, Garsed DW, George J, Fereday S, Nones K, Cowin P, Alsop K, Bailey PJ, Kassahn KS, Newell F, Quinn MC, Kazakoff S, Quek K, Wilhelm-Benartzi C, Curry E, Leong HS, Australian Ovarian Cancer Study G, Hamilton A, Mileshkin L, Au-Yeung G, Kennedy C, Hung J, Chiew YE, Harnett P, Friedlander M, Quinn M, Pyman J, Cordner S, O’Brien P, Leditschke J, Young G, Strachan K, Waring P, Azar W, Mitchell C, Traficante N, Hendley J, Thorne H, Shackleton M, Miller DK, Arnau GM, Tothill RW, Holloway TP, Semple T, Harliwong I, Nourse C, Nourbakhsh E, Manning S, Idrisoglu S, Bruxner TJ, Christ AN, Poudel B, Holmes O, Anderson M, Leonard C, Lonie A, Hall N, Wood S, Taylor DF, Xu Q, Fink JL, Waddell N, Drapkin R, Stronach E, Gabra H, Brown R, Jewell A, Nagaraj SH, Markham E, Wilson PJ, Ellul J, McNally O, Doyle MA, Vedururu R, Stewart C, Lengyel E, Pearson JV, Waddell N, deFazio A, Grimmond SM and Bowtell DD: Whole-genome characterization of chemoresistant ovarian cancer. Nature 521: 489-494, 2015. PMID: 26017449, DOI: 10.1038/nature14410

31 Vaidyanathan A, Sawers L, Gannon AL, Chakravarty P, Scott AL, Bray SE, Ferguson MJ and Smith G: ABCB1 (MDR1) induction defines a common resistance mechanism in paclitaxeland olaparib-resistant ovarian cancer cells. Br J Cancer 115: 431441, 2016. PMID: 27415012, DOI: 10.1038/bjc.2016.203

32 Shaffer BC, Gillet JP, Patel C, Baer MR, Bates SE and Gottesman MM: Drug resistance: still a daunting challenge to the successful treatment of AML. Drug Resist Updat 15: 62-69, 2012. PMID: 22409994, DOI: 10.1016/j.drup.2012.02.001

33 Bleau A-M, Hambardzumyan D, Ozawa T, Fomchenko EI, Huse JT, Brennan CW and Holland EC: PTEN/PI3K/Akt pathway regulates the side population phenotype and ABCG2 activity in glioma tumor stem-like cells. Cell Stem Cell 4: 226-235, 2009. PMID: 19265662, DOI: 10.1016/j.stem.2009.01.007

34 Hirschmann-Jax C, Foster AE, Wulf GG, Nuchtern JG, Jax TW, Gobel U, Goodell MA and Brenner MK: A distinct "side population" of cells with high drug efflux capacity in human tumor cells. Proc Natl Acad Sci USA 101: 14228-14233, 2004. PMID: 15381773, DOI: 10.1073/pnas.0400067101.
35 Chun SY, Kwon YS, Nam KS and Kim S: Lapatinib enhances the cytotoxic effects of doxorubicin in MCF-7 tumorspheres by inhibiting the drug efflux function of $\mathrm{ABC}$ transporters. Biomed Pharmacother 72: 37-43, 2015. PMID: 26054673, DOI: 10.1016/j.biopha.2015.03.009

36 Huang B, Fu SJ, Fan WZ, Wang ZH, Chen ZB, Guo SJ, Chen JX and Qiu SP: PKCepsilon inhibits isolation and stemness of side population cells via the suppression of ABCB1 transporter and PI3K/Akt, MAPK/ERK signaling in renal cell carcinoma cell line 769P. Cancer Lett 376: 148-154, 2016. PMID: 27037060, DOI: 10.1016/j.canlet.2016.03.041

37 Lee HH, Bellat V and Law B: Chemotherapy induces adaptive drug resistance and metastatic potentials via phenotypic CXCR4expressing cell state transition in ovarian cancer. PLoS One 12: e0171044, 2017. PMID: 28196146, DOI: 10.1371/journal.pone .0171044

38 Eyre R, Harvey I, Stemke-Hale K, Lennard TW, Tyson-Capper $\mathrm{A}$ and Meeson AP: Reversing paclitaxel resistance in ovarian cancer cells via inhibition of the ABCB1 expressing side population. Tumour Biol 35: 9879-9892, 2014. PMID: 24993095, DOI: 10.1007/s13277-014-2277-2

39 Zhang H, Wang J, Cai K, Jiang L, Zhou D, Yang C, Chen J, Chen D and Dou J: Down-regulation of gene MDR1 by shRNA to reverse multidrug-resistance of ovarian cancer A2780 cells. J Cancer Res Ther 8: 226-231, 2012. PMID: 22842366, DOI: 10.4103/0973-1482.98975

40 Szakacs G, Annereau JP, Lababidi S, Shankavaram U, Arciello A, Bussey KJ, Reinhold W, Guo Y, Kruh GD, Reimers M, Weinstein $\mathrm{JN}$ and Gottesman MM: Predicting drug sensitivity and resistance: profiling $\mathrm{ABC}$ transporter genes in cancer cells. Cancer Cell 6: 129-137, 2004. PMID: 15324696, DOI: 10.1016/j.ccr.2004.06.026

41 Cordon-Cardo C, O'Brien JP, Boccia J, Casals D, Bertino JR and Melamed MR: Expression of the multidrug resistance gene product (P-glycoprotein) in human normal and tumor tissues. J Histochem Cytochem 38: 1277-1287, 1990. PMID: 1974900, DOI: $10.1177 / 38.9 .1974900$

42 Thiebaut F, Tsuruo T, Hamada H, Gottesman MM, Pastan I and Willingham MC: Cellular localization of the multidrugresistance gene product P-glycoprotein in normal human tissues. Proc Natl Acad Sci USA 84: 7735-7738, 1987. PMID: 2444983

43 Robey RW, Pluchino KM, Hall MD, Fojo AT, Bates SE and Gottesman MM: Revisiting the role of $\mathrm{ABC}$ transporters in multidrug-resistant cancer. Nat Rev Cancer 18: 452-464, 2018. PMID: 29643473, DOI: 10.1038/s41568-018-0005-8

44 Binkhathlan Z and Lavasanifar A: P-glycoprotein inhibition as a therapeutic approach for overcoming multidrug resistance in cancer: current status and future perspectives. Curr Cancer Drug Targets 13: 326-346, 2013. PMID: 23369096
Received January 7, 2019

Revised January 21, 2019 Accepted January 22, 2019 